\title{
OPTIMAL ALLOCATION OF HEAT TRANSFER AREA FOR A REFRIGERATION PLANT
}

\section{Tong-Bou Chang}

Associate Professor, Department of Mechanical Engineering, Southern Taiwan University of Technology, YungKang City, Tainan County, Taiwan, R.O.C., tbchang@mail.stut.edu.tw

Follow this and additional works at: https://jmstt.ntou.edu.tw/journal

Part of the Mechanical Engineering Commons

\section{Recommended Citation}

Chang, Tong-Bou (2007) "OPTIMAL ALLOCATION OF HEAT TRANSFER AREA FOR A REFRIGERATION PLANT," Journal of Marine Science and Technology. Vol. 15: Iss. 1, Article 6.

DOI: 10.51400/2709-6998.2031

Available at: https://jmstt.ntou.edu.tw/journal/vol15/iss1/6

This Research Article is brought to you for free and open access by Journal of Marine Science and Technology. It has been accepted for inclusion in Journal of Marine Science and Technology by an authorized editor of Journal of Marine Science and Technology. 
OPTIMAL ALLOCATION OF HEAT TRANSFER AREA FOR A REFRIGERATION PLANT

Acknowledgements

This study is partially supported by the National Science Council of the Republic of China under contract NSC94-2212-E-218-017. 


\title{
OPTIMAL ALLOCATION OF HEAT TRANSFER AREA FOR A REFRIGERATION PLANT
}

\author{
Tong-Bou Chang*
}

Key words: refrigeration plant, optimal area allocation, internal irreversibility.

\begin{abstract}
For an internally reversible refrigerant plant, Bejan proposed an optimal way of dividing the area ratio of heat transfer for the hot end and cold end heat exchangers. In the present study, an optimal design of a refrigeration plant has been developed by considering both the external and internal irreversibilities. The internal irreversibility is modeled by a heat bypass which represents the actual internal heat leak and the friction losses due to mechanism movement. A more general formulation than previous study of optimal area-ratio is obtained in this study. For the case of no internal irreversibility, this formulation is exactly the same as that obtained by Bejan.
\end{abstract}

\section{INTRODUCTION}

For analyzing the thermodynamic cycles, reversible cycles provide the upper bound on the performance criteria. Irreversibilities due to friction, heat transfer and other sources are classified into internal and external irreversibilities. External irreversibilities occur outside the system boundaries during the process, while internal irreversibilities occur within the boundaries of the system. Finite-time thermodynamics is more practical than classical thermodynamics for analyzing the thermal efficiency of a heat engine and the $C O P$ of a refrigeration plant. Due to the advance in finite-time thermodynamics, many researchers have studied the optimal performance of an endoreversible Carnot thermal cycle. The consequence of incorporating finitetime heat transfer processes into an otherwise ideal thermodynamic cycle was elegantly demonstrated by Curzon and Ahlborn [6]. They considered the finite rates of heat transfer to and from a Carnot heat engine. For an internally refrigeration plant of a fixed heat extraction rate, Bejan $[1,2]$ found the optimal way of

Paper Submitted 02/07/06, Accepted 05/12/06. Author for Correspondence: Tong-Bou Chang. E-mail: tbchang@mail.stut.edu.tw.

*Associate Professor, Department of Mechanical Engineering, Southern Taiwan University of Technology, YungKang City, Tainan County, Taiwan, R.O.C. dividing the heat transfer area between the two heat exchangers depends on the total amount of heat exchanger area available and the relative external characteristics of the hot end and cold end heat exchangers. In general, the optimal $A_{H}$ is not equal to $A_{L}$. Wu et al. [8] analyzed and optimized the cooling load of the endoreversible steady flow refrigeration cycles. Chen et al. [5] analyzed the cooling load and COP performance of endoreversible regenerated Brayton refrigeration cycles coupled to constant and variable temperature heat reservoirs.

For the internal irreversible thermodynamic cycles, Chen [3] has introduced an irreversibility parameter to include the internal irreversibilities of a heat engine and evaluated the maximum efficiency and the maximum power output for the heat engine. Chen et al. [4] presented a steady-state flow model, which incorporates the internal irreversiblities caused by pipe friction and turbulence. Recently, Hsieh and Chiou [7] used an internal heat transfer model to represent the losses due to internal irreversibilities for a heat engine.

The conductances of both condenser and evaporator are expensive commodities, because they both increase with the size of the respective heat exchangers. For a realistic refrigeration plant with internal irreversibilities, it is a challenge to divide the total area between the hot end $A_{H}$ (where the heat dissipation is conducted) and the cold end $A_{L}$ (where the heat absorption is executed) in order to maximize the refrigerator's performance.

In this study, the more general formulations than previous study are derived to represent the optimal area allocation and the corresponding maximum $C O P$ for a realistic refrigeration plant under a fixed cooling rate. If the internal irreversibility is neglected, the optimal area allocation obtained by the present formulation is consistent with Bejan's result $[1,2]$.

\section{ANALYSIS}

\section{Thermodynamic model}

Consider a steady-state refrigeration cycle sketched in Figure 1 which operates between thermal reservoirs 


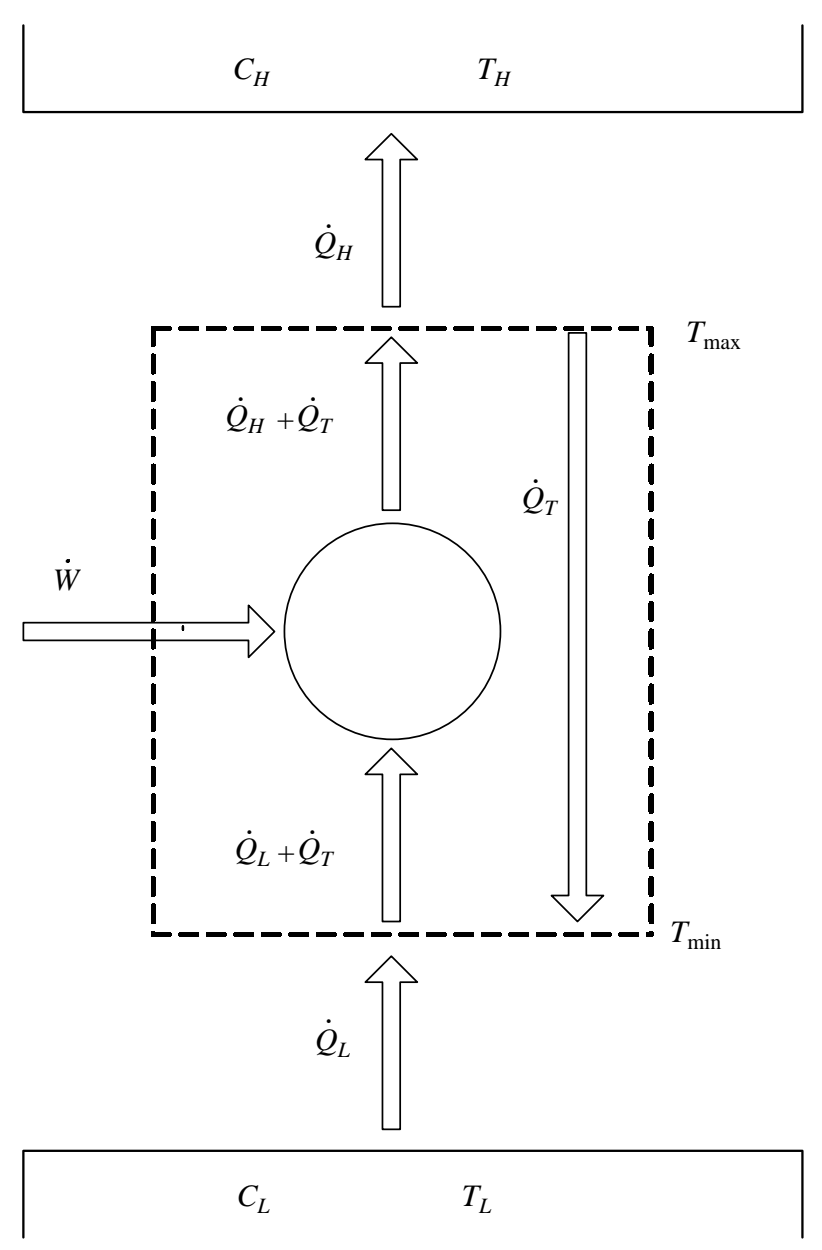

Fig. 1. Model of a realistic refrigeration plant with two heat exchangers.

at temperature $T_{H}$ and $T_{L}$. The second law efficiency of the refrigeration plant can be written as:

$$
\eta_{I I}=\frac{C O P}{(C O P)_{C}} \leq 1
$$

where $C O P$ is the coefficient of performance, which is defined as the ratio of the heat extraction rate over the input power, $\dot{Q}_{L} / \dot{W}$, and $(C O P)_{c}$ is the $C O P$ of a Carnot refrigerator, which can be written as

$$
(\mathrm{COP})_{C}=\frac{T_{L}}{T_{H}-T_{L}}
$$

In Carnot refrigeration cycle, all of the thermodynamic processes are assumed reversible, which implies there is no temperature difference between heat reservoir and internal working fluid during the heat transfer process. For an actual refrigeration plant, the heat transfer occurs under a finite temperature difference. The lowest temperature of refrigerator's working fluid, $T_{\min }$, is lower than the temperature of refrigerated space,
$T_{L}$. At the lower end in Figure 1, the evaporator heat transfer rate $\dot{Q}_{L}$ can be expressed in terms of a heat exchanger effectiveness based on the evaporator temperature

$$
\dot{Q}_{L}=\varepsilon_{L} C_{L}\left(T_{L}-T_{\min }\right)
$$

where

$$
\varepsilon_{L}=1-\exp \left(-\frac{U_{L} A_{L}}{C_{L}}\right)
$$

In the above formulation, $\varepsilon_{L}$ is applied for the phase change heat transfer process (either evaporation or condensation).

Similarly, the highest temperature of working fluid, $T_{\max }$, is larger than the ambient temperature, $T_{H}$. The heat dissipation from the hot fluid in the condenser to the ambient can be expressed by

$$
\dot{Q}_{H}=\varepsilon_{H} C_{H}\left(T_{\max }-T_{H}\right)
$$

where

$$
\varepsilon_{H}=1-\exp \left(-\frac{U_{H} A_{H}}{C_{H}}\right)
$$

Since $T_{\max }>T_{H}$ and $T_{L}>T_{\min }$, the processes are no longer reversible when the refrigeration plant is absorbing and dissipating the heat. Since Eqs.(3) and (5) represent the heat transfer rates across the refrigerator's boundaries, we may consider that there exists external irreversibility in the refrigerator.

When the external irreversibilities are accounted further, the coefficient of performance of the refrigeration plant should be written as

$$
C O P=\frac{\dot{Q}_{L}}{\dot{W}} \leq\left(\frac{T_{\max }}{T_{\min }}-1\right)^{-1}
$$

Now, the equal part of $\leq$ sign in the above equation represents the cycle executed by the working fluid is assumed to be an internal reversible (or called endoreversible cycle).

In an actual refrigeration plant, the losses due to the movement friction and various heat leakages will make the endoreversible assumption invalid. These losses will penalize the net cooling ability and decrease the efficiency of the refrigeration plant. In this study, the heat bypass, $\dot{Q}_{T}$, is used to represent the internal heat leak and the friction losses, see Figure 1. 


\section{Optimal heat transfer area}

The required input power $(\dot{W})$ for a refrigeration plant is directly relates to the absorbing heat transfer rate $\left(\dot{Q}_{L}\right)$ and rejecting heat transfer rate $\left(\dot{Q}_{H}\right)$. Eqs.(3) and (5) represent the fundamental heat transfer models for the actual heat exchangers at the cold and hot ends of the refrigeration plant, respectively. If the total heat transfer area is fixed, i.e.

$$
A_{H}+A_{L}=A=\text { constant }
$$

The ratio of the hot-end area to the total area is denoted by $y$ and is given by:

$$
y=\frac{A_{H}}{A}
$$

Therefore, from Eq. (8), it can be shown that:

$$
1-y=\frac{A_{L}}{A}
$$

The question of how to divide the constant area $A$ into $A_{H}$ and $A_{L}$ in order to maximize the coefficient of performance for an internal reversible refrigeration plant was studied by Bejan [1,2].

If the internal heat losses can be modeled as $\dot{Q}_{T}$, from Figure $1, \dot{Q}_{L}+\dot{Q}_{T}$ is the amount of heat flow rate which is actually extracted by the refrigeration plant. However, the net cooling rate is only $\dot{Q}_{L}$. Therefore, the present study defined the ratio of the amount of heat extraction rate over the input power as endoreversible coefficient of performance

$$
C O P_{\text {endo }}=\frac{\dot{Q}_{L}+\dot{Q}_{T}}{\dot{W}}=\left(\frac{T_{\max }}{T_{\min }}-1\right)^{-1}
$$

Comparing Eqs.(7) and (10), it is clearly shown that $\dot{Q}_{T}$ represents the total internal irreversibility.

Substituting $\dot{W}=\dot{Q}_{H}-\dot{Q}_{L}$ into Eq.(10) will get

$$
\frac{T_{\max }}{\dot{Q_{H}}+\dot{Q}_{T}}=\frac{T_{\min }}{\dot{Q}_{L}+\dot{Q}_{T}}
$$

Dividing Eq.(5) by $\dot{Q}_{H}-\dot{Q}_{T}$ will get

$$
\frac{\dot{Q}_{H}}{\left(\varepsilon_{H} C_{H}\right)\left(\dot{Q}_{H}+\dot{Q}_{T}\right)}=\left(\frac{T_{\max }}{\dot{Q}_{H}+\dot{Q}_{T}}-\frac{T_{H}}{\dot{Q}_{H}+\dot{Q}_{T}}\right)
$$

Similarly dividing Eq.(3) by $\dot{Q}_{L}-\dot{Q}_{T}$ will yield

$$
\frac{\dot{Q}_{L}}{\left(\varepsilon_{L} C_{L}\right)\left(\dot{Q}_{L}+\dot{Q}_{T}\right)}=\left(\frac{T_{L}}{\dot{Q}_{L}+\dot{Q}_{T}}-\frac{T_{\min }}{\dot{Q}_{L}+\dot{Q}_{T}}\right)
$$

Combining Eqs.(12) and (13) with the relation of Eq.(11) gives

$$
\begin{aligned}
\frac{T_{H}}{\dot{Q}_{H}+\dot{Q}_{T}} & =\frac{T_{L}}{\dot{Q}_{L}+\dot{Q}_{T}} \\
& -\left(\frac{\dot{Q}_{H}}{\left(\varepsilon_{H} C_{H}\right)\left(\dot{Q}_{H}+\dot{Q}_{T}\right)}+\frac{\dot{Q}_{L}}{\left(\varepsilon_{L} C_{L}\right)\left(\dot{Q}_{L}+\dot{Q}_{T}\right)}\right)
\end{aligned}
$$

Regarding $\dot{Q}_{L}-\dot{Q}_{T}$ as a fixed value, maximization of the $C O P$ is equivalent to minimizing the $\dot{W}$ (or minimizing the $\dot{Q}_{H}-\dot{Q}_{T}$. It means the left hand side of Eq.(14) should be maximized. In the other words, the expression in brackets on the right side of Eq.(14) should be minimized. The present study set $Z$ to represent the amount of this bracket and define the internal irreversibility of the realistic refrigeration plant as $\xi$,

$$
\xi=\frac{\dot{Q}_{T}}{\dot{Q}_{L}} \geq 0
$$

or

$$
\dot{Q}_{T}=\xi \dot{Q}_{L}
$$

Using Eqs.(4) and (6) and (10a), the bracket of Eq. (14), Z, can be expressed as

$$
\begin{aligned}
Z & =\frac{\dot{Q}_{L}+W}{\left(\varepsilon_{H} C_{H}\right)\left((\xi+1) \dot{Q}_{L}+W\right)}+\frac{1}{\left(\varepsilon_{L} C_{L}\right)(\xi+1)} \\
& =\frac{\left(C_{H}\right)^{-1}}{1-\exp (-y N)}\left(\frac{C O P_{\text {endo }}+1+\xi}{(\xi+1) C O P_{\text {endo }}+1+\xi}\right) \\
& +\frac{\left(C_{L}\right)^{-1}}{1-\exp \left(\frac{-(1-y) N\left(U_{L} / U_{H}\right)}{C_{L} / C_{H}}\right)} \times \frac{1}{(\xi+1)}
\end{aligned}
$$

where $N$ is the number of heat transfer units based on the total area and the room temperature parameters,

$$
N=\frac{U_{H} A}{C_{H}}
$$


Specifying the ratios $C_{L} / C_{H}, C_{L} / C_{H}, N, \xi$, the optimal area ratio can be obtained by minimizing $Z$ with respect to $\mathrm{y}$ and set it to be zero.

$\frac{C_{L}}{C_{H}} \times \frac{-\left(N \times \exp \left(-y_{\text {opt }} N\right)\right)}{\left(1-\exp \left(-y_{\text {opt }} N\right)\right)^{2}} \times \frac{C O P_{\text {endo }}+1+\xi}{(\xi+1) C O P_{\text {endo }}+1+\xi}$

$$
+\frac{N U_{L} / U_{H}}{C_{L} / C_{H}} \times \frac{\exp \left(\frac{-\left(1-y_{\text {opt }}\right) N U_{L} / U_{H}}{C_{L} / C_{H}}\right)}{\left(1-\exp \left(\frac{-\left(1-y_{o p t}\right) N U_{L} / U_{H}}{C_{L} / C_{H}}\right)\right)^{2}}
$$$$
\times \frac{1}{(\xi+1)}=0
$$

where $y_{\text {opt }}$ is the optimal area ratio $A_{H, \text { opt }} / A$, which can be solved by the numerical method.

Eq. (18) represents that the optimal area ratio $A_{H, \text { opt }} / A$ is function of $C_{L} / C_{H}, C_{L} / C_{H}, N, \xi$ and $C O P_{\text {endo }}$ for a realistic refrigeration plant.

For the special case of no internal irreversibility $(\xi=0)$, Eq.(18) can be written as

$\frac{C_{L}}{C_{H}} \times \frac{-\left(N \times \exp \left(-y_{o p t} N\right)\right)}{\left(1-\exp \left(-y_{\text {opt }} N\right)\right)^{2}}+\frac{N U_{L} / U_{H}}{C_{L} / C_{H}}$

$$
\times \frac{\exp \left(\frac{-\left(1-y_{\text {opt }}\right) N U_{L} / U_{H}}{C_{L} / C_{H}}\right)}{\left(1-\exp \left(\frac{-\left(1-y_{o p t}\right) N U_{L} / U_{H}}{C_{L} / C_{H}}\right)\right)^{2}}=0
$$
[2].

which is exactly the same as that obtained by Bejan

\section{RESULTS AND DISCUSSIONS}

Since $\dot{Q}_{H}$ is larger than $\dot{Q}_{L}, C_{L} / C_{H}$ and $C_{L} / C_{H}$ are usually less than unity. Figure 2 shows the $A_{H, \text { opt }} / A$ decreases as $C_{L} / C_{H}$ increases for the case of $N=1, C_{L} /$ $C_{H}=1$ (both condenser and evaporator are air cooled). The values of $A_{H, \text { opt }} / A$ are only slightly larger than 0.5 , $A_{H, \text { opt }} / A$ is larger when heat loss ratio increased. Which means the area at hot end should be slightly larger than that at cold end. In the other words, the design value of
$A_{H}=A_{C}$ commonly used in many application areas is still appropriate. Figure 2 also shows a higher $C O P_{\text {endo }}$ resulting a smaller $A_{H, \text { opt }} / A$. This result indicates the optimal area allocation is less sensitive when the plant's $C O P$ is higher.

For a typical air-conditioning system, the values of $T_{H}=35^{\circ} \mathrm{C}, T_{\text {max }}=50^{\circ} \mathrm{C}, T_{L}=12^{\circ} \mathrm{C}, T_{\text {min }}=5^{\circ} \mathrm{C}$ are used to plot $A_{H, o p t} / A$ and $C O P$ vs. $\xi$ at $N=1, C_{L} / C_{H}=1$ and $C_{L} / C_{H}=1$, see Figure 3. At $T_{H}=35^{\circ} \mathrm{C}(308 \mathrm{~K})$, $T_{L}=12^{\circ} \mathrm{C}(285 \mathrm{~K})$, the Carnot $C O P$ is $(C O P)_{C}=\frac{T_{L}}{T_{H}-T_{L}}$

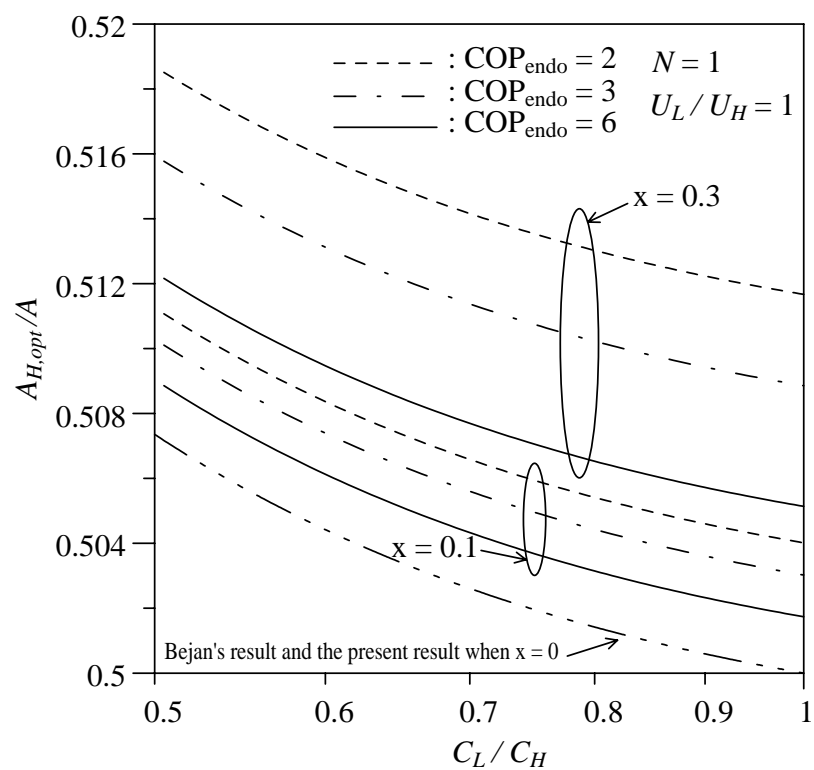

Fig. 2. Optimal area ratio $A_{H, \text { opt }} / A$ for the heat exchangers of a realistic refrigeration plant at $N=1, U_{L} / U_{H}=1$.

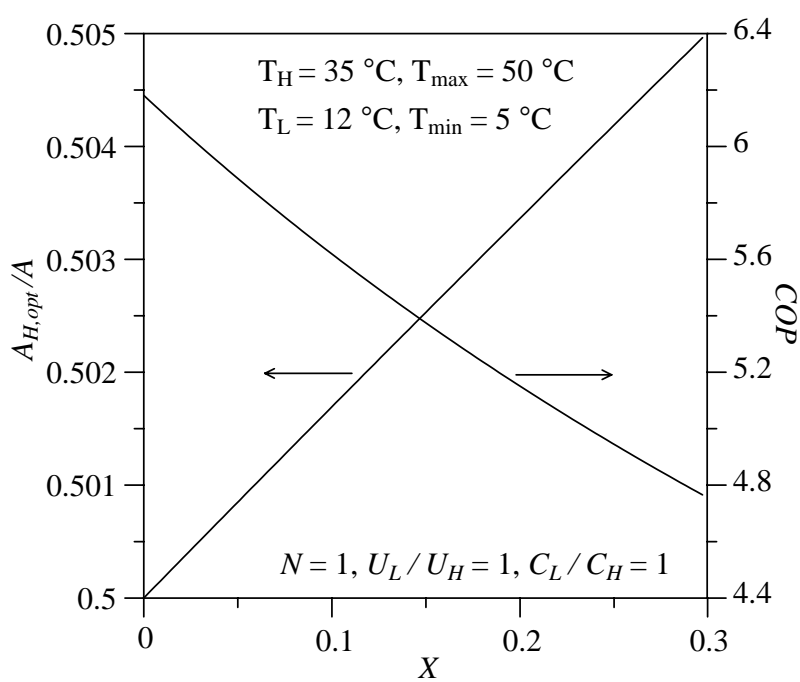

Fig. 3. $A_{H, o p t / A}$ and $C O P$ vs. $\xi$ for a typical air-conditioning system. 


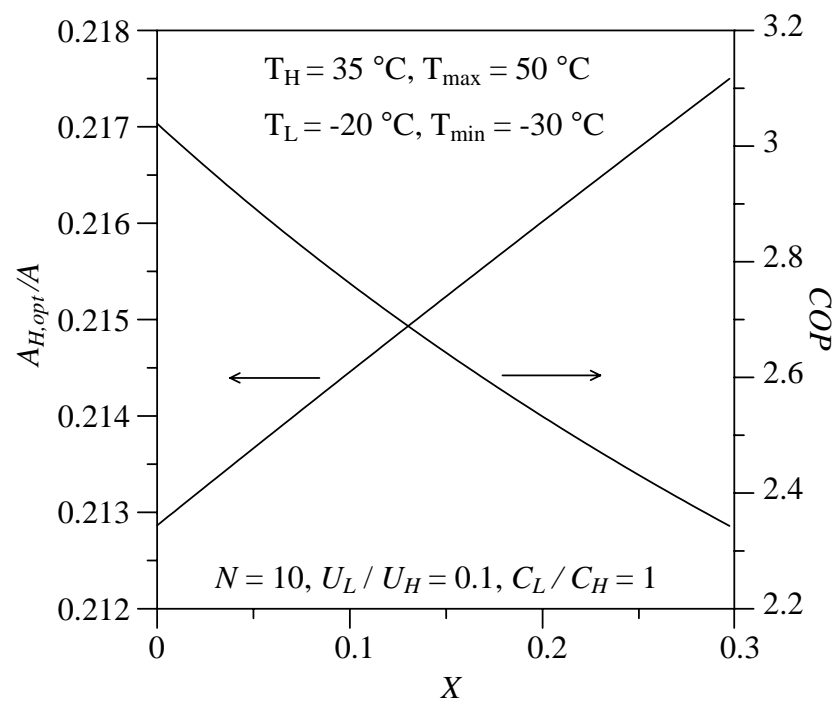

Fig. 4. $A_{H, ~ o p t / A}$ and $C O P$ vs. $\xi$ for a typical freezing system.

$=12.4$, the $C O P$ of internal reversible cycle (when $\xi=$ 0 in Figure 3) is 6.18 and decreased to 4.76 when $\xi=$ 0.3. Again, all of $A_{H, \text { opt }} / A$ value is not too far away from evenly allocation value $\left(A_{H} / A=0.5\right.$ or $\left.A_{H} / A_{L}\right)$.

Figure 4 shows the $A_{H \text {, opt }} / A$ and $C O P$ vs. $\xi$ for a typical freezing system which operates at $T_{H}=35^{\circ} \mathrm{C}$, $T_{\text {max }}=50^{\circ} \mathrm{C}, T_{L}=-20^{\circ} \mathrm{C}, T_{\min }=-30^{\circ} \mathrm{C}$ with $N=10, C_{L} /$ $C_{H}=1$ and $U_{L} / U_{H}=0.1$ (when condenser is cooled by a cooling tower). Figure 4 shows the $C O P$ will decrease from $3.04(\xi=0)$ to $2.34(\xi=0.3)$. Because it is rather difficult to extract a fixed load from a colder space. The value of $A_{H, o p t} / A$ is also decreases to $0.213(\xi=0)$ or to $0.218(\xi=0.3)$ because the heat transfer coefficient at hot end (condenser) is greatly enhanced by the watercooling. However, the difference of $A_{H, \text { opt }} / A$ due to the degree of heat loss is not very obvious.

\section{CONCLUSION}

A heat bypass model is used to represent the internal irreversibility for a refrigeration plant, and the more general formulation of optimized area ratio and $C O P$ is obtained in this study. The results calculated from this formulation indicate that the degree of internal irreversibility can penalize the plant's $C O P$, but has only slightly effect on the optimized area allocation.

\section{ACKNOWLEDGEMENT}

This study is partially supported by the National Science Council of the Republic of China under contract NSC94-2212-E-218-017.

\section{Nomenclature}

$A \quad$ total heat transfer area $A=A_{H}+A_{L}$

$A_{H} \quad$ heat transfer area of refrigerator's hot-end

$A_{L} \quad$ heat transfer area of refrigerator's cold-end

$C O P \quad$ coefficient of performance

$C O P_{C} \quad$ coefficient of performance of Carnot refrigerator

$C O P_{\text {endo }}$ endoreversible coefficient of performance

$C_{L} \quad$ heat capacity of cold end

$C_{H} \quad$ heat capacity of hot end

$N$ number of heat transfer unit based on the total area

$\dot{Q}_{L} \quad$ heat absorbing rate to refrigeration plant

$\dot{Q}_{H} \quad$ heat dissipation rate from refrigeration plant

$\dot{Q}_{T} \quad$ internal heat loss

$T_{L} \quad$ temperature at refrigerated space

$T_{H} \quad$ temperature at ambient

$T_{\text {min }} \quad$ lowest temperature of refrigerator's working fluid

$T_{\max } \quad$ highest temperature of refrigerator's working fluid

$U_{H} \quad$ total heat transfer coefficient based on $A_{H}$

$U_{L} \quad$ total heat transfer coefficient based on $A_{L}$

$\dot{W} \quad$ input power of refrigeration plant

$\xi \quad$ internal irreversibility $\dot{Q}_{T} / \dot{Q}_{L}$

$\varepsilon_{L} \quad$ heat exchanger effectiveness of evaporator

$\varepsilon_{H} \quad$ heat exchanger effectiveness of condenser

\section{REFERENCE}

1. Beian, A., "Theory of Heat Transfer-Irreversible Refrigeration Plants," International Journal of Heat and Mass Transfer, Vol. 32, pp. 1631-1639 (1989).

2. Bejan, A., Tsatsaronis, G., and Moran, M., Thermal Design \& Optimization, John Wiley \& Sons, pp. 319-320 (1996).

3. Chen, J., "The Maximum Power Output and Maximum Efficiency of an Irreversible Carnot Heat Engine," Journal of Physics D: Applied Physics, Vol. 27, pp. 11441149 (1994).

4. Chen, L., Sun, F., Wu, C., and Kiang, R.L., "A Generalized Model of a Real Refrigerator and Its Performance," Applied Thermal Engineering, Vol. 17, No. 4, pp. 401412 (1997).

5. Chen, L., Wu, C., and Sun, F., "Finite Time Thermodynamic Performance of an Isentropic Closed Regenerated Brayton Refrigeration Cycle," International Journal of Energy Environment Economics, Vol. 4, pp. 261-274 (1997).

6. Curzon, F.L. and Ahlborn, B., "Efficiency of a Carnot 
Engine at Mavimum Power Output," American Journal of Physics, Vol. 43, No. 1, pp. 22-24 (1975).

7. Hsieh, Y.C. and Chiou, J.S., "Optimal Allocation of Heat Transfer Area for A Heat Engine," Journal of Mechanics,
Vol. 21, No. 1, pp. 1-4 (2005).

8. Wu, C., Chen, L., and Sun, F., "Optimization of Steady Flow Refrigeration Cycles," International Journal of Ambient Engergy, Vol. 17, pp. 199-206 (1996). 